\section{The wing stent facilitates repeat bile duct cannulation for multiple stent insertion}

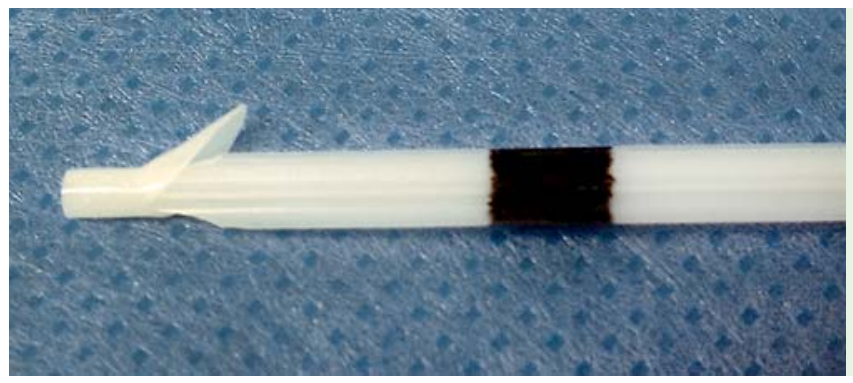

Fig. 1 Wing stent $(10 \mathrm{Fr}, 12 \mathrm{~cm})$ with soft pliable retention flaps and a radiopaque black marker for accurate placement. The stent channels fluid along its winged perimeter, which may increase its patency rates.

The primary disadvantage of conventional plastic biliary stents is their short patency rate [1], as they are prone to biofilm buildup within the central lumen of the stent, resulting in impaired bile flow [2]. The wing stent (ViaDuct; GI Supply, Camp Hill, Pennsylvania, USA) was engineered to overcome this problem ( $\bullet$ Fig. 1).

The wing stent is a lumenless stent in which bile is channeled along the exterior winged grooves, theoretically reducing the risk of occlusion ( Fig. 1) [3,4]. Computer modeling studies have shown that the wing stent offers a larger surface area for flow, a higher flow velocity, and increased flow rates compared with conventional plastic stents. A pilot study reported the successful use of the wing stent for endoscopic biliary drainage in five patients with malignant biliary obstruction, all of whom experienced a significant decline in bilirubin at 2 weeks and resolution of biliary dilation by radiologic imaging [3].

The endoscopic placement of multiple stents over time for patients with benign biliary strictures has been shown to be an effective therapy for stricture resolution [5]. The placement of multiple stents can be technically challenging for a number of reasons, including failure of repeat biliary cannulation after the first stent insertion. This can occur if a small biliary sphincterotomy was performed and/or the positioning of the first stent prevents the necessary angulation of the biliary cannula or sphincterotome. This problem

\section{Video 1}

After the wing stent is placed in the bile duct, the wire is placed in the channel between two wings of the stent and advanced into the bile duct. A second stent can subsequently be placed over the wire in the standard fashion. can be overcome by initially placing a 7Fr or 10-Fr wing stent into position using a push catheter until the radiopaque black marker at the distal end of the stent is visualized at the biliary orifice. Subsequently, rapid repeat biliary cannulation is achieved by advancing a guidewire into the groove between two wings of the insitu wing stent and into the proximal bile duct. A conventional plastic stent is then placed over the wire and advanced into the bile duct. Additional stents can then be placed in similar manner ( Fig. 2 , - Video 1).

Competing interests: None

Endoscopy_UCTN_Code_TTT_1AR_2AZ

\section{A. Khashab, V. K. Singh,}

A. M. Lennon, S. A. Giday

Division of Gastroenterology and Hepatology, Department of Medicine, The Johns Hopkins Medical Institutions, Baltimore, Maryland, USA

\section{References}

1 Costamagna G, Pandolfi M. Endoscopic stenting for biliary and pancreatic malignancies.J Clin Gastroenterol 2004; 38: 59-67

2 Costa L, Bracco P, Vada $S$ et al. A chemical analysis of the clogging process of polymeric biliary endoprostheses. Biomaterials 2001; 22: $3113-3119$

3 Raju GS, Sud R, Elfert AA et al. Biliary drainage by using stents without a central lumen: a pilot study. Gastrointest Endosc 2006; 63: 317-320

4 Buscaglia JM, Parashette KR, Okolo PI 3rd. Treatment of hemobilia-induced biliary obstruction by transpapillary gallbladder and common bile duct drainage using three biliary winged stents. Endoscopy 2008; 40: E58

5 Costamagna G, Pandolfi M, Mutignani $M$ et al. Long-term results of endoscopic management of postoperative bile duct strictures with increasing numbers of stents. Gastrointest Endosc 2001; 54: 162-168
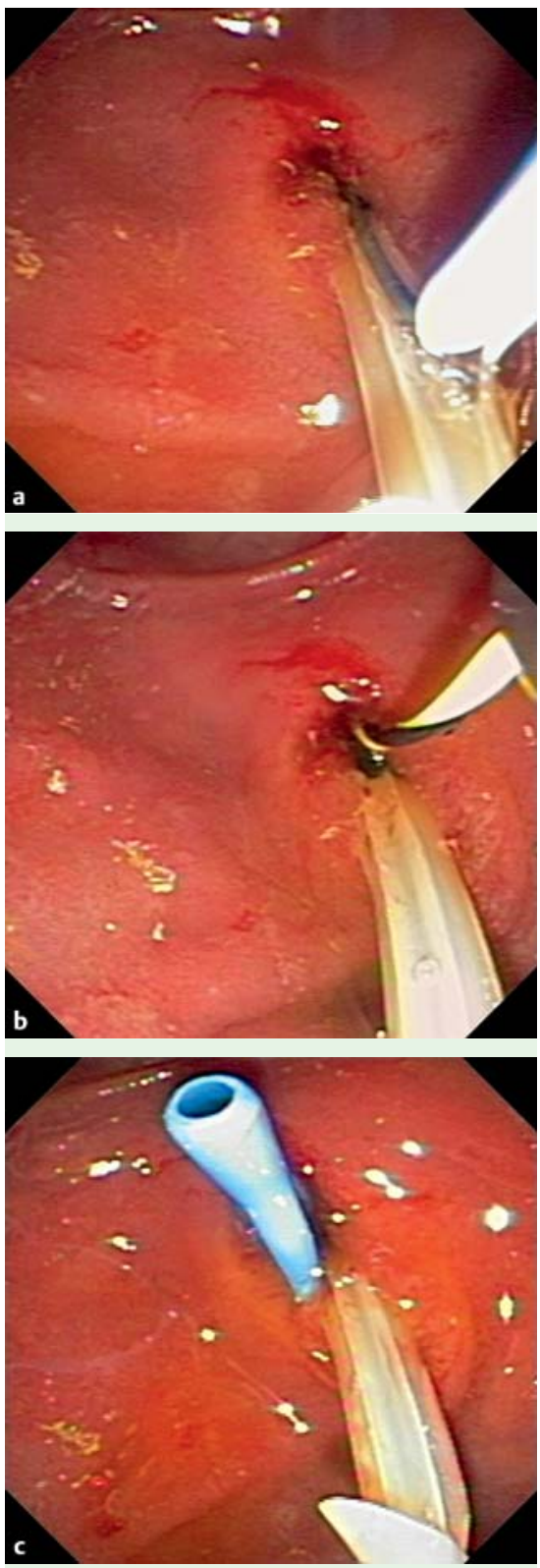

Fig. 2 a After the wing stent is placed in the bile duct, the wire is placed in the channel between two wings of the stent. $\mathbf{b}$ The wire is then advanced into the bile duct. $\mathbf{c}$ A second stent can subsequently be placed without difficulty over the wire in standard fashion.

\section{Bibliography}

DOI $10.1055 / \mathrm{s}-0030-1255982$

Endoscopy 2010; 42: E337

(c) Georg Thieme Verlag KG Stuttgart · New York . ISSN 0013-726X

\section{Corresponding author}

\section{S. Giday, MD}

Center for Digestive Health

1817 North Mills Avenue

Orlando

FL 32803

USA

Fax: +01-410-614-0231

mkhasha1@jhmi.edu 